\title{
THE ALTERATION OF THE OPERATING PARAMETERES OF THE AEROCYCLONE DEPENDING ON THE GEOMETRY OF THE VORTEX FINDER
}

\author{
Blanka Orosz \\ BSc student, University of Miskolc, Institute of Energy Engineering and Chemical Machinery \\ 3515 Miskolc, Miskolc-Egyetemváros, e-mail: borosz99@gmail.com \\ Máté Petrik \\ assistant lecturer, Institute of Energy Engineering and Chemical Machinery, University of Miskolc \\ 3515 Miskolc, Miskolc-Egyetemváros, e-mail:vegypet@uni-miskolc.hu \\ Gábor L. Szepesi \\ associate professor, Institute of Energy Engineering and Chemical Machinery, University of Miskolc \\ 3515 Miskolc, Miskolc-Egyetemváros: szepesi@uni-miskolc.hu
}

\begin{abstract}
The engineering practice in general requires the ability to recognize the possible hazards associated with the coordinated production process. Solid particles found in the air can potentially be one of these, therefore it is fundamental to deal with the risk posed by certain types of dusts. An industrial cyclone is an equipment which is designed to separate the hazardous material from the harmless matter within the air. First and foremost the efficiency of a cyclone is determined substantially by the operating parameters. Certain geometries of the device however, such as the vortex finder can also have a significant role. The experiment conducted revolves around a CFD simulation to determine the efficiency of the apparatus based on different geometries in general and also regarding the vortex finder. The results indicate that the length of the vortex detector has a more significant effect, than the overall geometry.
\end{abstract}

Keywords: aerocyclon, vortex finder

\section{Introduction}

Solid particles that pollute the air in many places in everyday life, commonly referred to as dust matter, and they can be of natural or artificial origin. In the engineering practice, dusts of artificial origin pose a real risk.

Depending on their size and chemical composition, they can cause various health and environmental hazards and industrial accidents. In terms of potential harmful effects, several types of dusts can be distinguished according to laws (Esta, 2021). These include E, A and U dust.

E-dust: also known as the respirable fraction of dust, the particles of this size can easily enter the human body through the mouth and the nose. The best-known natural E-powder is pollen and in the industrial environment it is cement and sand. In this case the particle size is smaller than $100 \mu \mathrm{m}$.

A-dust: means the fraction of dust that also enters the alveole of the lungs. This includes many types of smoke and quartz particles smaller than $5 \mu \mathrm{m}$.

U-dust: the finest powder, built up by nanoparticles. 
The inhalable fraction is the most dangerous because it gets deposited in the airways and consequently impairs the lung's ability to exchange air. Over a certain period of time inadequate oxygen uptake leads to cardiovascular disease. The best-known industrial accident caused by dust is the socalled dust explosion. During such an occurrence explosion, small particles with a high specific surface area mix with air, creating a combustible mixture that ignites in the presence of an ignition source and then explodes. Three things must be present simultaneously in space and time for this process to occur:

1. sufficient amount of powder,

2. sufficient oxygen,

3. ignition source.

In general, it is true that dusts of combustible materials will also be combustible and these can be divided into three groups according to their flammability. They can be dusts of easily combustible materials, dusts of moderately combustible materials and dusts of not easily combustible materials.

Powders in the food industry (flour, cocoa, sugar) are highly flammable and combustible substances, and small amounts of these are enough to cause an explosion. There are dusts of combustible materials, which do not float in the air for long periods of time, so they pose a much lower risk of dust explosion. The probability of occurrence can be reduced by limiting the presence of one of the three aforementioned conditions. It is highly difficult to limit the amount of dust, because the distribution of dust in the equipment will not be constant, so it is possible that only a small volume of the equipment will exceed the explosion limit concentration.

Minimizing the ignition source is also problematic, because a small spark can be enough for an ignition. However, it is much easier to reduce the amount of oxygen by using inert gases. Such inert gases are nitrogen and carbon dioxide. Since even this does not reduce the chance of an explosion to zero, it is always necessary to incorporate (Zólyomi et al., 2016) additional slit-openings. Explosions most often occur in silo cells, followed by dust collectors. The risks mentioned above make it advisable to separate the powders from the gas stream, but separation may also be necessary in different technological processes. Valuable products can be extracted in powder form during grinding and spray drying. Dust separation is an operation used to separate gas-solid systems. The apparatus used in this procedure is called dust separation equipment. One possible way of dust separation is the use of cyclones or multicyclones.

\section{Historical review}

M. Morse's "cyclone-shaped dust collector" was patented in the USA and Germany in 1886. After the First World War (Koncz 1970), the dust load got much more significant and therefore the cyclones became more and more important. In 1939, the cyclones created by Shephard and Lapple were 2D2D, which means (Siménfalvi et al. 2013) that the height of the cylindrical and conical parts of the cyclone is twice the diameter of the cylindrical part. In 1979, Parnell and Davis were the first to use the 1D3D design, which had a much more favourable boundary cut-off size than the 2D2D design cyclones.

Recently there are also many scientific papers investigating how the operating parameters of a cyclone are affected by the use of different geometries or ratios. One of these scientific papers was published by Dang Khoi Lea, Joon Yong Yoonb (Joon et al., 2020), where the authors placed stubs with different inflow volumes and positions at points on the cyclone's mantle. In the first case, the stumps were located at the same circumferential points (C4), while in the second, they followed a spiral path (N4). The study showed that the degree of dust separation was improved in both cases compared to the 
conventional single tangentially positioned stub, but the best dust separation was associated with the cyclone design N4.
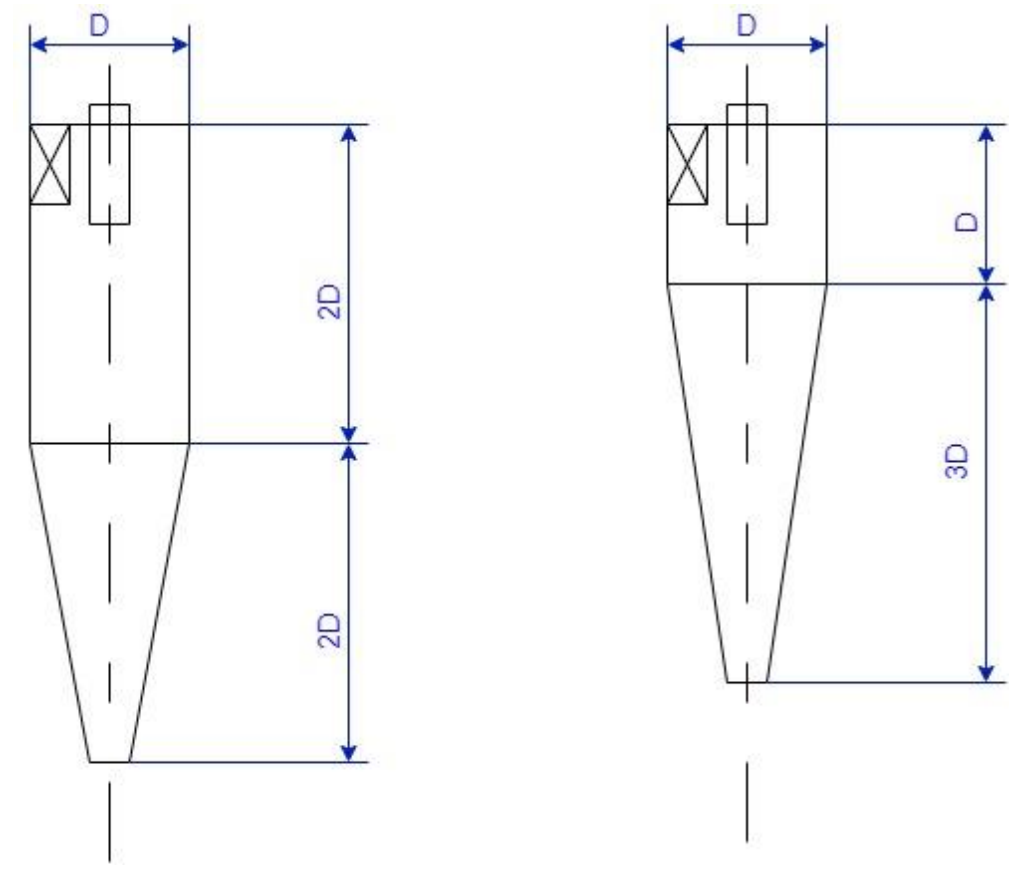

Figure 1. Differently shaped cyclones a) Shephard and Lapple, b) Parnell and Davis
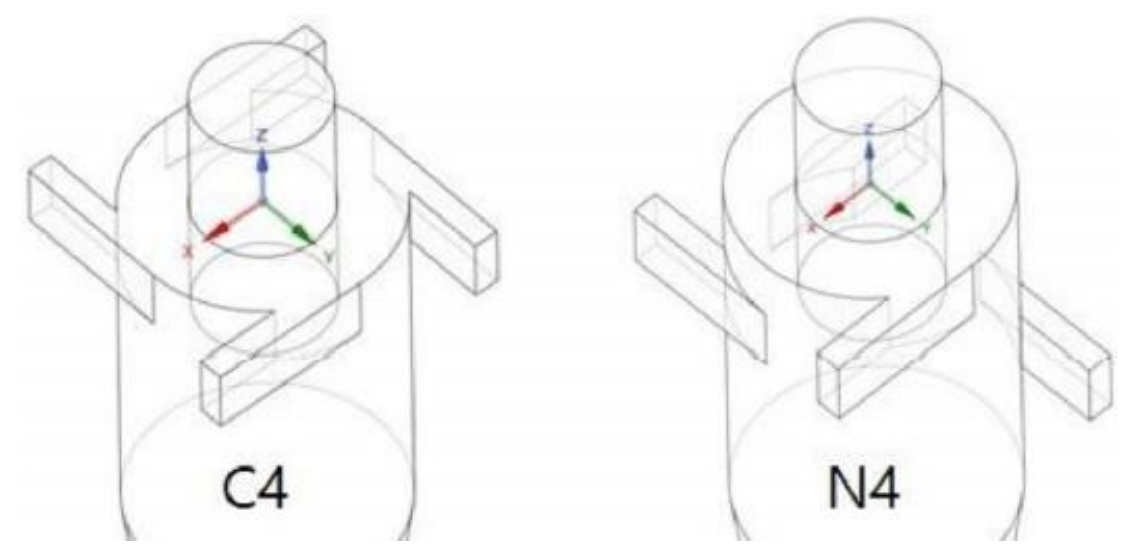

Figure 2. Differently located stumps

S. Bernardo et al. (Mori et al., 2006) also investigated the effects of a tangentially located stub connection. The stub was attached to the mantle at $30^{\circ}, 45^{\circ}$ and then $60^{\circ}$ relative to the conventional one. The result of the experiment is that the degree of dust removal can be increased to $77.2 \%$ instead of the initial $54.4 \%$ with the $45^{\circ}$ deviation.

Research published by Fuping Qiana, Yanpeng Wu (Wu et al., 2009) also shows that by tilting the stub at $45^{\circ}$ to the perpendicular position, we can reduce the pressure difference by $15 \%$ compared to conventional cyclone designs. 


\section{The cyclone structure}

The special feature and advantage of cyclones is their simple design, which does not include moving parts. Due to their structural design, the dusty gas entering the cyclone is transported in the tangential direction by a pipe (1) and thus is forced into orbit through the cylindrical shale section (2), then the larger particles hit the wall and lose their energy in the conical part (3) sliding down into the dust collector. The particles that are not separated pass through the vortex finder (4) either into the airspace or into further purification equipment.

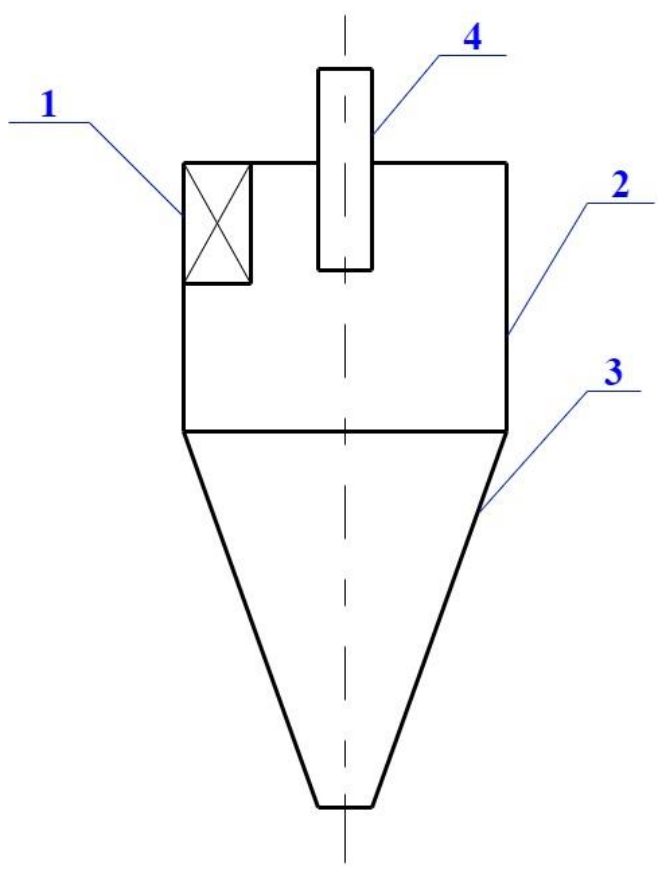

Figure 3. Parts of the cyclone

Based on this, one of the most important operating parameters of the cyclone is the cut-off size $\left(d_{h}\right)$ which is the smallest particle size that is $100 \%$ separated during the operation of the cyclone. The formula (Siménfalvi et al., 2013) published by Rosin, Rammler and Intelmann:

$$
d_{h}=\frac{3}{2} \cdot \sqrt{\frac{\eta \cdot D^{2}}{8 \cdot w_{b} \cdot h \cdot \rho}\left[1-\left(\frac{d_{1}}{D}\right)^{4}\right]}
$$

Where:

$\eta$ - dynamic viscosity $[\mathrm{Pa} \cdot \mathrm{s}]$,

$\rho$ - the particle density $\left[\frac{\mathrm{kg}}{\mathrm{m}^{3}}\right]$,

$w_{b}$ - the inlet velocity $\left[\frac{\mathrm{m}}{\mathrm{s}}\right]$,

$d_{1}$ - diameter of the vortex finder $[\mathrm{m}]$ and

$D$ - cylinder diameter $[\mathrm{m}]$.

The next important operational parameter is the pressure loss of the cyclone $(\Delta p)$, on the definition of which there is a large body of literature. The earliest theory is the theory of Barth (Tarján et al., 1973), 
assumes that the pressure loss is made up of two different parts. One of these is the pressure loss in the separating space, and the other is the pressure loss in the vortex finder.

$$
\Delta p=\left(\varepsilon_{1}+\varepsilon_{2}\right) \cdot \frac{\rho}{2} \cdot v_{t 0}^{2}=\left(\theta_{1}+\theta_{2}\right) \cdot \frac{\rho}{2} \cdot v_{0}^{2}
$$

Where:

$\varepsilon_{1}$ - pressure loss of the separation field with respect to the tangential velocity,

$\varepsilon_{2}$ - pressure loss of the vortex finder with respect to the tangential velocity,

$\rho$ - density of the solid particle $\left[\frac{\mathrm{kg}}{\mathrm{m}^{3}}\right]$,

$v_{t 0}$ - the tangential velocity $\left[\frac{\mathrm{m}}{\mathrm{s}}\right]$,

$\theta_{1}$ - average discharge velocity,

$\theta_{2}$ - relative to the discharge velocity,

$v_{0}$ - discharge velocity $\left[\frac{\mathrm{m}}{\mathrm{s}}\right]$.

The flows in the cyclone are turbulent, swirling and chaotic. During the calculations simplifications have been applied (Helmeczi 2010), which are described below:

- gravitiy force was ignored,

- the particles do not affect each other's motion,

- Stoke's law is true for the motion of the particles,

- spherical particles are assumed (equivalent sphere diameter),

- the particle distribution and gas velocity are consistent in the inlet cross section.

The results of the calculations do not give an exact solution, so we need to perform numerical flow simulations to get accurate results. Thanks to computational fluid dynamics (CFD) simulations, the flow pattern in the cyclone can be accurately represented.

\section{The simulation}

A three-dimensional computational fluid dynamics was used to describe the gas and gas-solid flow in the cyclone. Due to the flow conditions, the k-omega model was used because it provides accurate results for both the near-wall flows and the external flows. The simulation compared the operating parameters of two cyclones. The difference was the length of the vortex finder. One cyclone has the dimensions as recommended in the literature $(\mathrm{C} 1)$, the other cyclone has a vortex finder of a different length $(\mathrm{C} 2)$ than recommended.

\subsection{Velocity distributions in the $z-y$ and $x-z$ plane}

The important velocities for dust removal in a cyclone are the tangential and axial velocities. The following pictures (Figure 4, Figure 5) show the velocity components in the cyclone. In both the tangential and axial cases, the maximum velocity occurred in the vortex finder.

For the longer vortex finder (C2), the maximum speed in the cyclone is reduced to $70.3 \%$ of the original. Thus, the residence time of the particles increased within the cyclone. The velocity in the dust collector hopper environment is zero, so the degree of dust removal should not be affected by backflows. 

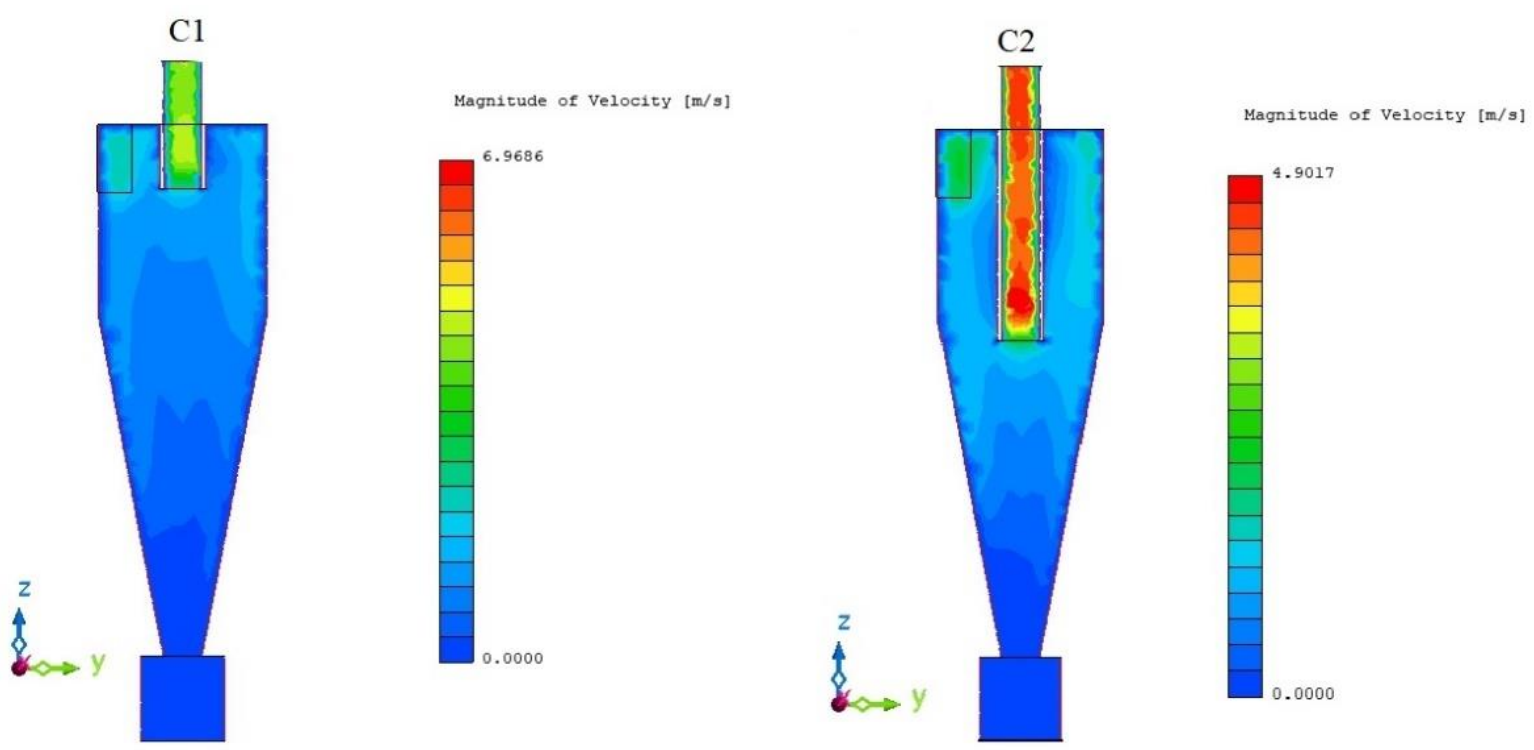

Figure 4. Velocity distribution in the z-y component
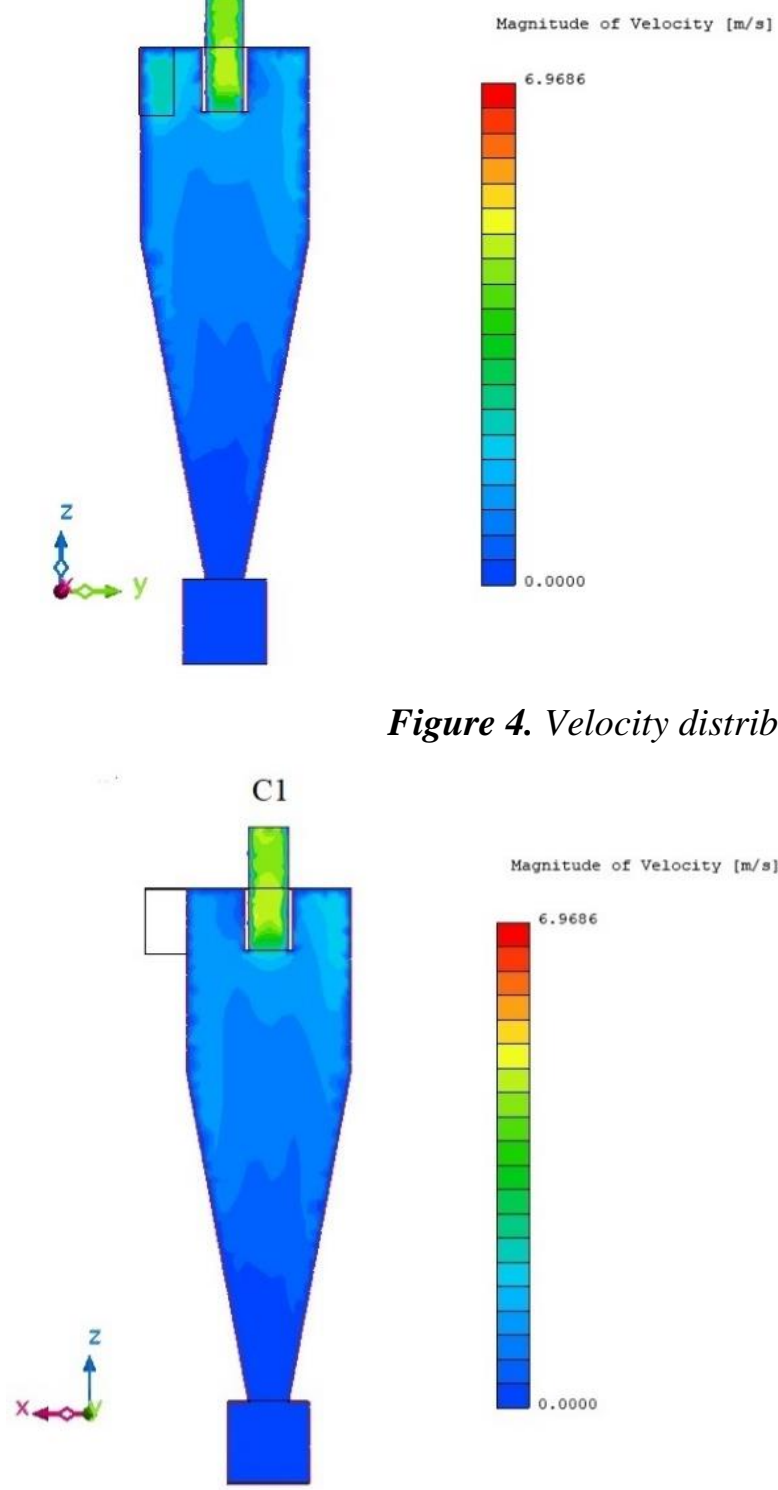

$\mathrm{C} 2$
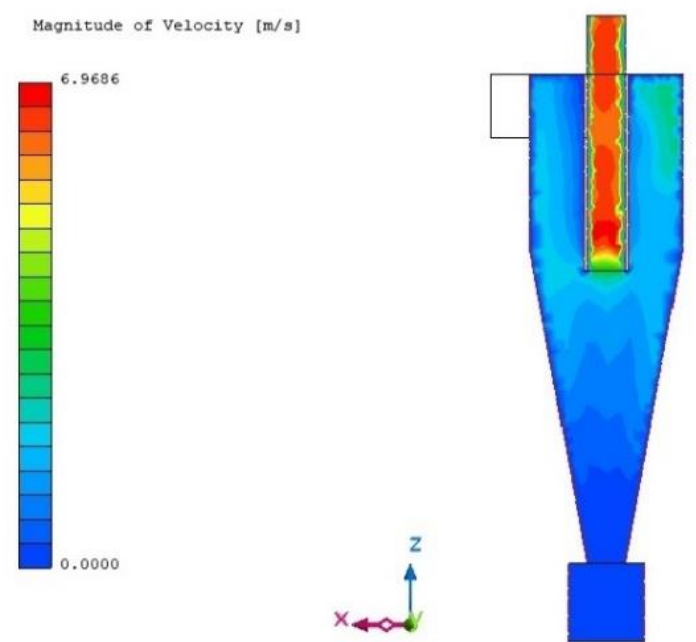

Magnitude of Velocity $[\mathrm{m} / \mathrm{s}]$

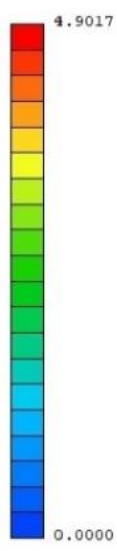

Figure 5. Velocity distribution in the $x$-z component

\subsection{Pressure distributions in the $x-z$ plane}

Cyclone pressure loss is interpreted as drag, so this value should be as small as possible. The pressure loss is also reduced to the original $95 \%$. The negative pressure in the vortex detector can be interpreted as a suction effect, which was $48 \%$ higher in case $\mathrm{C} 2$ than in case $\mathrm{C} 1$. 

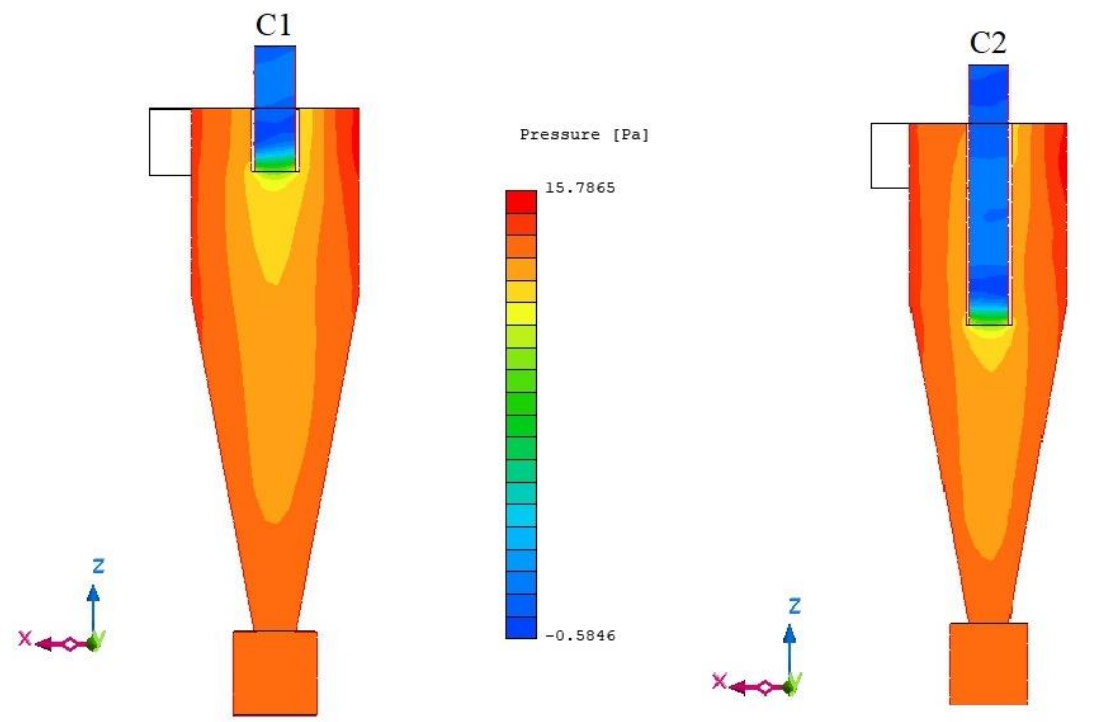

Pressure $[\mathrm{Pa}]$

Figure 6. Pressure distribution in the $x-z$ component
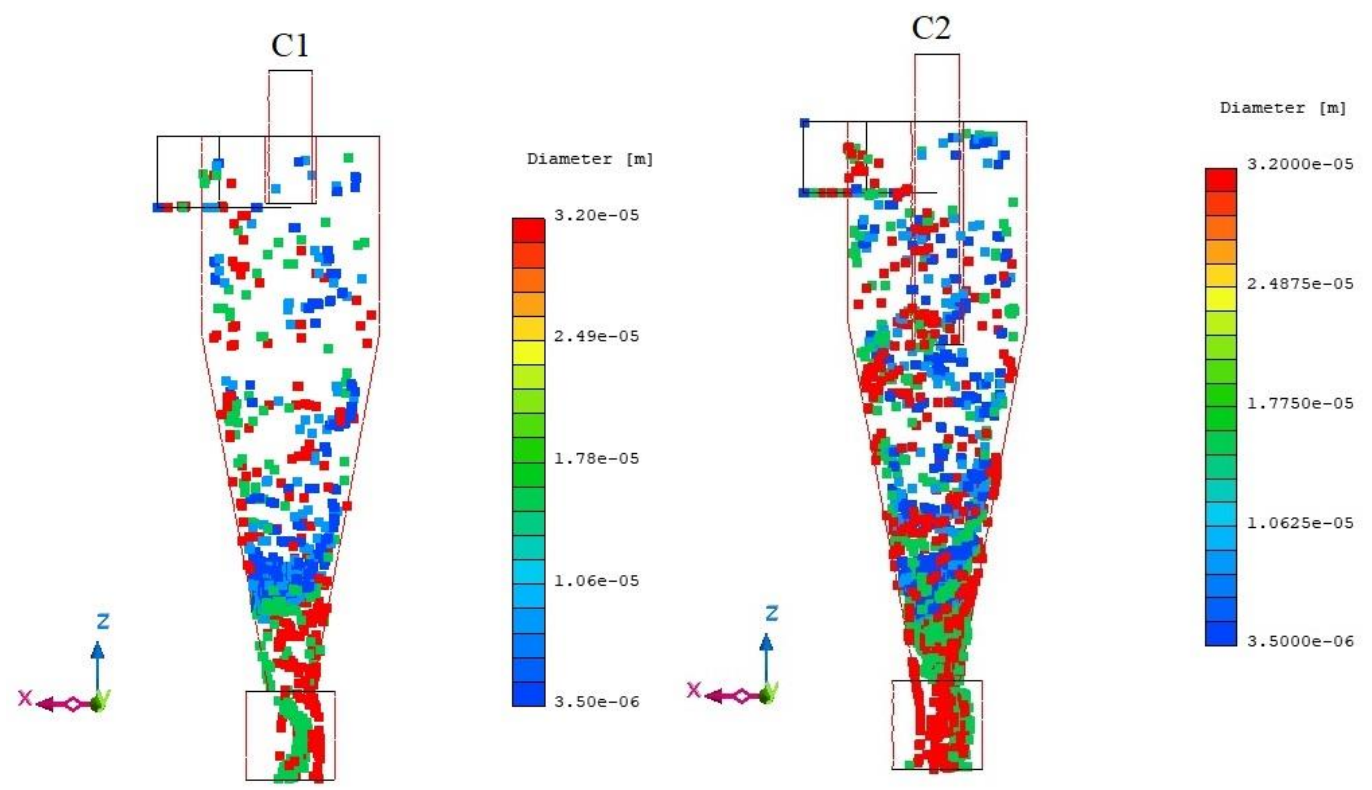

Figure 7. Particle boundaries

\subsection{Particle separation}

The powder mixture contained particles of $3,5 \cdot 10^{-6} \mathrm{~m}, 4 \cdot 10^{-6} \mathrm{~m}, 8 \cdot 10^{-6} \mathrm{~m}, 1,6 \cdot 10^{-5} \mathrm{~m}$ and $3,2 \cdot 10^{-5} \mathrm{~m}$ in size. Cyclone $\mathrm{C} 2$ has a dust collection rate of $98.5 \%$, compared to $96.5 \%$ for cyclone $\mathrm{C} 1$. In the case of $\mathrm{C} 2$, this meant 750 incoming particles, of which 735 were separated by the cyclone. Of the separated grains, 450 were larger and 285 were smaller than the calculated $6,3 \cdot 10^{-6} \mathrm{~m}$ limiting particle size. 


\section{Conclusion}

The article compares two cyclones, the difference between them being the length of the vortex finder tube. In the simulation, the efficiency of the boundary particle, the pressure drop and the separation were investigated. The simulation showed that the degree of dust removal can be increased by increasing the length of the vortex detector tube. The change in geometry did not significantly affect the pressure drop.

\section{Acknowledgements}

The research was supported by the Hungarian National Research, Development and Innovation Office under the project number K 134358.

\section{References}

[1] Tarján, G., Fejes, G. (1973). Vegyipari gépek és müveletek. Budapest, Tankönyvkiadó, pp. 402405.

[2] Koncz, I. (1970). Portalanitás és porleválasztás. Budapest, Müszaki Könyvkiadó, pp. 186-198.

[3] Siménfalvi, Z., Szepesi, G.: Porleválasztó ciklon nyomásveszteségének vizsgálata numerikus áramlástani módszerekkel. 2013 International Scientific Conference on advances is Mechanical Engineering, Debrecen.

[4] Esta Absaugtechnik (2021, July 04). https://www.esta.com/de/wissen/wissenabsauganlagen/was-ist-staub/?fbclid=IwAR2YOD9W0VYB4E0RctLJ35XOWzl1 ajxAcQGvhWkl4lb9N1pnNj3ZR9cvZs

[5] Zólyomi, G., Takács, K., Kuti, R. (2016). Porrobbanások veszélyei az élelmisziparban. Hadmérnök, 75-82.

[6] Helmeczi, R. (2010). Porleválasztó ciklonok vizsgálata. p. 11.

[7] Joon, Y. Y., Dang, K. L. (2020). Numerical investigation on the performance and flow pattern of two novel innovative designs of four-inlet cyclone separator. Chemical Engineering and Processing- Process Intensification.

[8] Mori, M., Peres, A. P., Dionísio, R. P., Bernardo, S. (2006). 3-D computational fluid dynamics for gas and gas-particle flows in a cyclone with different inlet section angles. Powder Technology, 190-200. https://doi.org/10.1016/j.powtec.2005.11.007

[9] Wu, Y., Quian, F. (2009). Effects of the inlet section angle on the separation performance of a cyclone. Chemical Engineering Research and Design, 1567-1572.

https://doi.org/10.1016/j.cherd.2009.05.001 